\title{
Cuticular lipids correlate with age and insemination status in queen honeybees
}

\author{
M. Babis ${ }^{1 a}$, L. Holman²a, R. Fenske ${ }^{3}$, M. Thomas ${ }^{4}$ \& B. Baer ${ }^{1 *}$ \\ ${ }^{1}$ Centre for Integrative Bee Research (CIBER), ARC CoE in Plant Energy Biology, \\ Bayliss building M310, The University of Western Australia, 6009 Crawley, \\ Australia \\ 2Division of Evolution, Ecology and Genetics, Research School of Biology, The \\ Australian National University, Canberra ACT 0200, Australia \\ ${ }^{3}$ Metabolomics Australia, ARC CoE in Plant Energy Biology, Bayliss building M310, \\ The University of Western Australia, 6009 Crawley, Australia \\ ${ }^{4}$ Centre of Evolutionary Biology, School of Animal Biology (M092), The University \\ of Western Australia, 6009 Crawley, Australia
}

a These authors contributed equally to the paper

*Author for correspondence:

Prof. Boris Baer

Centre for Integrative Bee Research

Bayliss building M310

The University of Western Australia

6009 Crawley, Australia

E-mail: boris.baer@uwa.edu.au

Phone: +61 864884495

Fax: $\quad+61864884401$ 


\section{ABSTRACT:}

Eusocial insects exhibit reproductive division of labour, in which one or a few queens perform almost all of the reproduction, while the workers are largely sterile and assist in rearing their siblings. Consequently, many of the colony's tasks (e.g. nest construction and brood rearing) should be modulated depending on whether the queen is fertile. Here, we tested whether queens' cuticular lipids could provide reliable signals of fertility in the honey bee Apis mellifera, as they do in other social Hymenoptera. Specifically, we tested whether cuticular lipids differ between virgin queens of different ages, and between queens exposed to different artificial insemination treatments being ejaculates, seminal fluid or saline control. Using gas chromatography-mass spectrometry we found 27 lipids: 21 different hydrocarbons, namely alkanes, alkenes and dienes, as well as six wax esters. The lipid profile changed dramatically in the first ten days after eclosion, and there were differences in lipid composition between virgin and artificially inseminated queens. Insemination with semen, seminal fluid or saline did not result in distinct chemical profiles. Our findings indicate that the physical stimulus of insemination was responsible for the observed changes in the cuticular profile in honey bee queens. Our results demonstrate that cuticular lipid profiles encode information on queen age, fertility and mating status, which could in principle be utilised by workers and rival queens.

KEY WORDS: Artificial insemination, chemical communication, cuticular hydrocarbons, fertility signal, queen pheromone. 


\section{INTRODUCTION}

Insects cover their cuticles with a complex mixture of organic chemicals that is thought to have evolved to protect against desiccation (Gibbs, 2002). These chemicals are predominantly hydrocarbons, though substances such as wax esters, aldehydes, ketones, sterols and alcohols are also often found (Copren et al., 2005; Lockey, 1988; Monnin, 2006; van Wilgenburg et al., 2011). Many of these cuticular chemicals have been evolutionarily co-opted to function in communication, and have pivotal roles in the social lives of their bearers (Blomquist and Bagnères, 2010; Howard and Blomquist, 2005).

Cuticular chemicals provide information to recognise and assess potential mates in a number of species. For example in the Australian field cricket, Teleogryllus oceanicus, they provide information on the sex, genetic compatibility (Thomas and Simmons, 2011) and mating status (Thomas and Simmons, 2009) of potential mating partners. Cuticular hydrocarbons are also used to identify specific individuals, such as the primary social partner or previous mates (d'Ettorre and Heinze, 2005; Mueller et al., 2003). They have been intensively studied in hymenopteran eusocial insects (the social bees, ants and wasps), because they are central to the regulation of social behaviours such as division of labour and nestmate recognition (Breed, 1998; Lorenzi et al., 1996; Peeters and Liebig, 2009; Singer, 1998; van Zweden and d'Ettore, 2010). Individuals within a colony share a largely homogeneous, colony-specific blend of cuticular lipids, referred to as the gestalt odour (Crozier and Dix, 1979), which allows individuals to discriminate between nestmates and non-nestmates in ants (Akino et al., 2004; Brandstaetter et al., 2008), wasps (Bruschini et al., 2011; Dani, 2009; 
Dapporto et al. 2006) and bees (Dani et al., 2005; Kather et al., 2011; Nunes et al., 2008). Cuticular hydrocarbons also change with female fecundity (de Biseau et al., 2004; Dietemann et al., 2003; Liebig et al., 2000; Monnin, 2006; Peeters et al., 1999; Sledge et al., 2001). Furthermore, molecules present on the cuticle differ between queens and workers, and are thought to be used by many species in the regulation of reproductive division of labour (Monnin, 2006). For example in the ant Lasius niger, mature queens produce a chemically distinct profile to workers, and experiments using synthetic hydrocarbons revealed that workers respond to one queen-specific hydrocarbon by remaining sterile and non-aggressive (Holman et al., 2010). In Aphaenogaster cockerelli ants, queens and sterile workers differ chemically but reproductive workers have similar hydrocarbons to queens, and are consequently attacked by their nest mates (Smith et al., 2009).

Honeybees (Apis mellifera) are an intriguing model system to examine the relationship between cuticular lipids and reproductive behaviour and physiology, because their mating biology has a number of characteristics that are rare or absent in other social insects. New colonies are founded through swarming, in which the resident mother queen leaves her hive to found a new colony together with a large number of workers (Rangel and Seeley, 2008; Seeley, 1995; Seeley et al., 2006). After her departure, several virgin queens may hatch in the queenless colony, and then engage in lethal fights. The sole surviving virgin queen engages in one or a few nuptial flights, during which she releases a volatile pheromone to attract males as potential mates (Tarpy and Mayer, 2009). After she has mated with a number of males, the workers accept the mated female as their new resident queen. Additionally, workers can rear replacement queens, possibly when they perceive that the resident queen is getting older and 
less fertile (Winston, 1987). All these characteristics of the biology of honeybee queens suggest a potential role for cuticular lipids in signalling to workers, and possibly to other queens and males. Honeybee queens have a well-studied volatile, glandular pheromone, the queen mandibular and queen retinue pheromone (QMP and QRP), which signals fertility (Kocher et al., 2009; Slessor et al., 1988; Strauss et al., 2008), attracts drones (Wanner et al., 2007) and influences worker behaviour and physiology (Le Conte and Hefetz, 2008). However, this does not rule out the possibility that cuticular hydrocarbons also play an important role, and their importance in fertility signalling is untested in honeybees.

Here we investigate whether lipids present on the cuticle of honey bee queens could be used to communicate information on queen age and fertility. Both ageing and insemination are known to have a multitude of effects on queen physiology (da Cruz-Landim et al., 2006; Kocher et al., 2008; Kocher et al., 2010) that might include changes in cuticular chemistry. To identify the effects of insemination, seminal fluid and sperm on queen cuticular lipids, we chemically analysed 10-day-old virgin queens and queens artificially inseminated with various substances. We also examined age-related changes in the cuticular lipids of newly-eclosed virgin queens.

\section{MATERIALS AND METHODS}

\section{Experimental animals}

All bees used for experiments were bred from A. mellifera stock at a bee yard at the University of Western Australia. Virgin queens were generated using 
standard bee keeping practises (Blum, 1992; Laidlaw and Page, 1997) by grafting 1- to 2-day-old larvae, i.e. larvae that have yet to undergo caste determination (Welch \& Lister, 2014), by picking them from the comb and transferring them into an artificial queen cell cup. Worker bees accept these artificial cups and rear the larvae into queens. All virgin queens in the study were offspring of the same mother queen, which was naturally mated. We kept emerging virgin queens in small plastic cages in four different queenless colonies and fed them ad libitum with a 1:1 mix of icing sugar and honey. All queens in the study were offspring of the same mother queen, and were likely to be

predominantly half-sisters (since $A$. mellifera queens mate with many males). Standardizing the genealogy and rearing environment of our experimental animals likely reduced residual variation and made it easier for us to detect differences between treatments and age classes.

\section{Age classes and insemination treatments}

First, to test whether cuticular lipid profiles change with age in recently-eclosed virgin queens, we chemically analysed queens that were freeze-killed at one $(\mathrm{n}=$ 12), six $(n=20)$ and ten $(n=16)$ days after emergence. The four colonies used for queen rearing contributed an equal number of queens to each of the three age treatments.

Second, we tested whether cuticular hydrocarbon profiles differ between ten-day-old virgins $(n=16)$ and same-aged queens that had been artificially inseminated with one of three different substances: Hayes solution ( $\mathrm{n}=27$ ), seminal fluid (without sperm; $n=20)$, or complete ejaculates ( $n=24)$. Again, the four colonies used for queen rearing contributed approximately equal numbers 
of queens to each treatment. Queens were randomly allocated to treatments and artificially inseminated with $6 \mu \mathrm{L}$ of one of the substances on day six posteclosion. We obtained ejaculates according to a standardised protocol used for artificial insemination (Mackenson, 1964). Briefly, we collected several hundred sexually mature drones from seven source colonies while they were leaving hives in the afternoon to participate in mating flights. Drones were killed with chloroform and manually stimulated by gently squeezing their abdomen until semen appeared at the end of the endophallus where it was picked up with a glass capillary connected to a syringe. One drone provides up to $1 \mu \mathrm{L}$ of sperm upon ejaculation. Males were picked randomly from the seven colonies and undiluted sperm for five inseminations was collected in one capillary. Prior to artificial insemination, we stored semen at room temperature in glass capillaries. To collect seminal fluid, we used a previously developed protocol (Niño et al., 2013; Nino et al., 2012). Briefly, we centrifuged non-diluted ejaculate samples collected from several hundred males for $25 \mathrm{~min}$ at $3000 \mathrm{rpm}$ and $4^{\circ} \mathrm{C}$ to separate the seminal fluid from sperm. The supernatant (pure seminal fluid) was collected and centrifuged again at $14000 \mathrm{rpm}$ for 10 minutes at $4^{\circ} \mathrm{C}$ to remove any remaining sperm. Seminal fluid samples were stored for $2-3$ days at $-80{ }^{\circ} \mathrm{C}$ prior to use in experiments, which keeps seminal fluid proteins intact (Baer et al., 2009).

Artificial inseminations were performed according to standardised techniques (Ruttner, 1976), but we avoided using $\mathrm{CO}_{2}$ as an anaesthetic, since $\mathrm{CO}_{2}$ is known to affect queen ovary development (Berger et al., 2005) and might influence therefore cuticular hydrocarbon profile (Ayasse et al., 1995; CuvillierHot et al., 2001; de Biseau et al., 2004; Sledge et al., 2001). Six-day-old queens 
were sedated by placing them in a refrigerator at approximately $8^{\circ} \mathrm{C}$ for 30 minutes. We then inseminated each queen with either $6 \mu \mathrm{L}$ of Hayes solution, seminal fluid or semen. After the insemination procedure, queens were allowed to recover and were kept individually in cages for 4 days, before being freezekilled. Non-inseminated control queens (i.e. the 10-day-old virgins mentioned above; $n=16$ ) were treated the same (i.e. were refrigerated and handled similarly to inseminated queens on day six post-eclosion, then freeze killed on day 10), except that they were not inseminated.

\section{Analysis of cuticular compounds}

To extract cuticular compounds, queens were individually immersed for 5 minutes in 3mL HPLC-grade hexane containing $8 \mathrm{mg} \mathrm{L}^{-1} n$-Docosane $\left(\mathrm{C}_{22}\right)$ as an internal standard in a glass vial. We injected $1 \mu \mathrm{L}$ of each sample into a gas chromatograph equipped with a mass spectrometer (GCMS, GC-7890A, MS5975C with inert XL MSD with Triple-Axis Detector; Agilent Technologies, Santa Clara, California, USA using a MPS2 XL-Twister autosampler; Gerstel GmbH \& Co. KG, Mülheim, Germany). The GC-MS was operated in splitless mode and fitted with a polar phase Stabilwax column (Restek; Bellefonte, Pennsylvania, USA) of $30 \mathrm{~m}$ length and $0.25 \mathrm{~mm}$ internal diameter using helium as a carrier gas at a flow rate of $1 \mathrm{~mL} / \mathrm{min}$. The temperature program was as follows: Hold at the initial temperature of $50{ }^{\circ} \mathrm{C}$ for one minute, then increase at a rate of $20{ }^{\circ} \mathrm{C} /$ minto a final temperature of $250{ }^{\circ} \mathrm{C}$, which was then held for 20 minutes. The transfer line temperature was set to $250^{\circ} \mathrm{C}$.

Peaks were analysed with MSD ChemStation software, version E.02.00.499. Detected peaks were identified based on their retention times and 
fragmentation patterns. We estimated the amount of each chemical present on the cuticle of each queen using semi-quantitative analysis by dividing the integrated area of each peak by that of the internal standard. Specifically, each peak was transformed by $3000 \times 0.008 \times A_{i} / A_{s}$, where $A_{i}$ is the area of the focal peak and $A_{s}$ is the area of the internal standard. The number 3000 arises because we injected $1 / 3000^{\text {th }}$ of the extract, while 0.008 refers to the injected mass of the internal standard in micrograms. This transformation gives an approximation of the mass of each cuticular lipid present on each queen in micrograms.

\section{Statistics}

All statistics were performed in R 3.0.2. We used a combination of multivariate and univariate statistics. Our multivariate statistics used non-metric multidimensional scaling (NMDS) to reduce the dimensionality of the data, implemented using the metaMDS function from the $\mathrm{R}$ package vegan. Prior to NMDS we computed a Euclidean distance matrix of the cuticular lipid data, and determined how many NMDS scores to generate using scree plots of stress versus number of dimensions. NMDS scores were then used as predictors in MANOVA and linear discriminant analysis. Our univariate analyses utilised linear models, and fits were verified using diagnostic plots; data were transformed where required to improve fit. Queen age was treated as a fixed factor throughout. 


\section{RESULTS}

Overall, we detected a total of 27 compounds in the queen cuticular extracts, 21 of which were hydrocarbons (ten alkanes, nine alkenes and two dienes) with chain lengths ranging from $\mathrm{C}_{21}$ to $\mathrm{C}_{33}$ (Fig. 1; Table S1). The remaining six compounds were wax esters with chain lengths ranging from $\mathrm{C}_{28}$ to $\mathrm{C}_{32}$. Figure 2 shows the abundances of each of the 27 compounds on the different classes of queens, while Figure 3 shows the proportion of the profile composed of each of the major lipid types.

\section{Change in the cuticular lipid profile with age in virgin queens}

The total amount of lipids present on virgin queens' cuticles increased strongly in the first 10 days after eclosion (linear model: $F_{2,45}=16.2, p<0.0001$; mean \pm SEM of abundance relative to the internal standard, one day: $28 \pm 2$, six days: 77 \pm 5 , ten days: $95 \pm 12$ ).

Age had strong effects on the proportion of the chemical profile composed of the three major types of lipid we detected, namely saturated hydrocarbons, unsaturated hydrocarbons and wax esters (Fig.3). The proportion of saturated hydrocarbons (alkanes) increased strongly with age $\left(F_{2,45}=37.7, p<0.0001\right)$, while the proportion of unsaturated hydrocarbons (alkenes and dienes) strongly decreased $\left(F_{2,45}=58.6, p<0.0001\right)$. There was also a large increase in the proportion of the profile composed of wax esters; in fact, esters were not present in detectable quantities in one-day-old virgin queens (linear model on arcsin square root transformed data: $F_{2,45}=15.8, p<0.0001$ ). 
Additionally, the average chain length of lipids (which we calculated by taking the sum of each chemical's chain length multiplied by its relative abundance) in the chemical profile was significantly lower in older virgin queens (linear model: $F_{2,45}=6.40, p=0.0036$ ). Model contrasts revealed that ten-day-old virgin queens had shorter-chained lipids than did six-day-old virgin queens $\left(\mathrm{t}_{45}=\right.$ $3.0, p=0.004)$, which had similar average lipid chain length to one-day-old virgin queens $\left(\mathrm{t}_{45}=0.56, \mathrm{p}=0.58\right)$.

MANOVA of three NMDS scores describing the composition of the cuticular lipid profile (NMDS stress: 0.03 , i.e. very low) revealed that the profile for virgin queens changed with age (Fig. 4A; Wilk's $\lambda=0.03$, df $=2,45$, p < 0.0001). Linear discriminant analysis using jackknife leave-one-out crossvalidation was able to correctly classify $85 \%$ of virgin queens into their age categories; all one-day-old virgin queens were correctly classified, with mistakes occurring in the discrimination of six- and ten-day-old virgin queens, suggesting that the one-day-old virgin queens were more chemically distinct from the older age classes than the six- and ten-day-old virgin queens were to each other. This pattern is visible in Figure 4A.

Lastly, in order to determine which chemicals changed with age, we performed linear models with age as a predictor and individual lipid peaks (expressed as an arcsin square root transformed proportion of the total profile) as the response. For $21 / 27$ peaks (Table S1), age was a significant predictor with $\mathrm{p}<0.001$, showing that the majority of the chemical profile changes with age (Fig. 2).

\section{Effect of artificial insemination treatment on queen cuticular lipids}


The insemination of queens with ejaculates, seminal fluid or Hayes saline had a significant effect on the total mass of lipids present on the cuticle compared to non inseminated virgin queens of the same age (linear model: $F_{3,83}$ $=2.93, \mathrm{p}=0.038$; abundance relative to internal standard: virgin: $95 \pm 12$, Hayes: $126 \pm 9$, seminal fluid: $142 \pm 13$, semen: $133 \pm 9$ ). Model contrasts suggested that this difference was predominantly due to the virgin queens having a lower amount of lipids than the other groups (virgins versus the other treatments: Hayes: $\mathrm{t}_{83}=1.97, \mathrm{p}=0.052$, seminal fluid: $\mathrm{t}_{83}=2.83, \mathrm{p}=0.0058$, semen: $\mathrm{t}_{83}=2.35$, $\mathrm{p}=0.021$ ), though note that the Hayes treatment was not significantly higher. The mass of lipids did not differ among the Hayes, seminal fluid and semeninseminated queens (all contrasts $\mathrm{p}>0.26$ ).

In contrast to the results for virgin queen age, the differences among queens in the different insemination treatments in the proportion of the profile composed of saturated and unsaturated hydrocarbons and wax esters were small (Figs 2, 3 and 4). The four insemination treatments differed significantly in the proportion of saturated hydrocarbons in queens' profiles (Fig. 3; linear model on arcsin square root transformed data: $F_{3,83}=2.77, p=0.046$ ), though contrasts revealed that only virgin queens and seminal-fluid inseminated queens differed significantly, with the latter having more than the former $\left(\mathrm{t}_{83}=2.16, \mathrm{p}=\right.$ 0.034; other contrasts $\mathrm{p}>0.87$ ). Similarly there was a difference in the proportion of unsaturated hydrocarbons in queens' profiles $\left(\mathrm{F}_{3,83}=3.36, \mathrm{p}=\right.$ 0.022), but contrasts showed that effect was driven by higher amounts of unsaturated hydrocarbons on virgin queens than seminal-fluid inseminated queens $\left(\mathrm{t}_{83}=2.91, \mathrm{p}=0.0046\right.$; other contrasts $\left.\mathrm{p}>0.36\right)$. There was no significant 
effect of insemination treatment on the proportion of the chemical profile composed of esters $\left(F_{3,83}=0.85, p=0.47\right)$.

As with the queen age study, insemination treatment affected the mean chain length of the chemical profile: virgin queens had a significantly lower mean chain length than Hayes ( $\mathrm{t}_{83}=2.00, \mathrm{p}=0.049$ ), seminal fluid $\left(\mathrm{t}_{83}=2.50, \mathrm{p}=\right.$ $0.014)$ or semen-inseminated queens $\left(\mathrm{t}_{83}=2.51, \mathrm{p}=0.014\right)$. Again, the three types of inseminated queens did not differ from one another (all $p>0.48$ ).

MANOVA suggested that insemination treatment had no effect on the relative amounts of compounds making up the chemical profile (Fig. 4B; Wilk's $\lambda$ $=0.89, \mathrm{df}=3,83, \mathrm{p}=0.34)$. Accordingly, linear discriminant analysis performed poorly, and was only able to correctly assign $29.9 \%$ of queens to the correct treatment based on their chemical profile. This pattern is shown in Figure 4B: ten-day-old virgins and the three insemination treatments clustered closely together.

Lastly, we again performed linear models with insemination treatment as a predictor and individual lipid peaks (expressed as an arcsin square root transformed proportion) as the response. For $6 / 27$ peaks, treatment was a significant predictor with $\mathrm{p}<0.05$, but only $1 / 27$ peaks had $\mathrm{p}<0.001$ (Table S1). Given the large amount of multiple testing, these results corroborate the MANOVA and suggest that either few or no peaks were substantially affected by insemination treatment. 


\section{DISCUSSION}

We found strong effects of age on queen cuticular lipids. Specifically, the total abundance of compounds increased three-fold in the ten days after eclosion, and the profile contained a greater proportion of shorter-chained-lipids. As expected from previous work linking esters and fertility, we also observed an increase in the proportion of wax esters with age. Discriminant analysis suggested that much of this change occurred shortly after eclosion, because one-day-old queens were more different to six- and ten-day-old queens than the latter two age classes were to each other.

We also found effects of insemination treatment, though these were subtler than the effects of age. Relative to controls, queens that were inseminated (whether with Hayes saline, seminal fluid or semen) had a larger mass of cuticular lipids, and their lipids were of longer average chain length. However, the changes were quite modest, and queens from the different insemination treatments could not be reliably discriminated by their cuticular lipid profiles in our statistical analyses. Moreover, we found no differences among the three types of inseminated queens in any of our tests: that is, Hayes saline induced the same changes in the lipid profile as did seminal fluid or semen. This result implies that the physical stimulus of insemination, rather than a physiological response to seminal fluid proteins or sperm for example (Baer et al., 2009), was responsible for the change in queens' cuticular lipids.

The age and reproductive status of a recently eclosed queen are important traits to workers. Honey bee workers display a number of behavioural and physiological responses to queens (Le Conte and Hefetz, 2008). For example, 
the workers form a "retinue" around the queen, and lick her and then distribute queen-derived odours around the colony by trophallaxis. Physiological responses to queens include the inhibition of worker ovarian activation (Hoover et al., 2003), as well as effects on learning (Vergoz et al., 2007) and gene expression (Grozinger et al., 2003). Since workers are predicted to derive greater inclusive fitness benefits from helping a queen that has been successfully inseminated (Keller and Nonacs, 1993), they should generally only benefit from producing a full range of responses to queens that are mated and fertile.

Moreover, virgin queens might also recognise each other via their cuticular lipids, and potentially use this information in case they engage in their famous lethal queen-queen fights (Cronin and Monnin, 2010). Identifying each other's age or insemination status might inform fighting strategy; for example, newly eclosed queens are likely more vulnerable, and queens might therefore be more likely to initiate fights with queens perceived to be younger than themselves. Conversely, it has been hypothesised that queens might sometimes acquiesce and allow themselves to be killed whenever fighting would harm their inclusive fitness (Cronin and Monnin, 2010). For example, a young, virgin queen confronted with an older, mated sister might sometimes benefit by allowing herself to be killed rather than risking injuring or killing her sister, who has already survived the risky mating flight.

Indeed, there is evidence that workers are able to detect and respond to queens based on a difference in insemination volume and/or genetic diversity of the semen (Richard et al., 2007; 2011b; Mattila et al., 2012) or insemination volume alone (Niño et al., 2012; 2013). Queens' volatile pheromones, e.g. the queen mandibular pheromone (QMP) (Keeling et al., 2003; Le Conte and Hefetz, 
2008), may allow workers to perceive queens' mating status. (Strauss et al., 2008) showed that some of components of QMP vary between virgin, dronelaying (i.e. fertile but not inseminated) and naturally-mated queens. Similarly, (Kocher et al., 2009) found that naturally-mated queens had more welldeveloped ovaries and a distinct pheromone profile from virgin or artificially inseminated queens (when measured 2 days after insemination), though saline and semen insemination had indistinguishable effects on these traits. The results of Kocher et al, 2009 are similar to ours: insemination affected queens' volatile odours, and it appears that the physical stimulus of insemination is sufficient to produce the effect because saline caused as much of a change as semen. Also, Kocher et al.'s (2009, see also Niño et al., 2012; 2013) result that the physical stimulus of insemination causes queens to activate their ovaries aids interpretation of our data. Ovarian activation is associated with cuticular lipids in many insects (Howard and Blomquist, 2005; Monnin, 2006; Peeters and Liebig, 2009), and our result that insemination caused substantial changes in the lipid profile suggests that this is also true of honey bees.

Taken with these previous studies of volatile queen pheromones, our study suggests that cuticular lipids could therefore play an important complementary role in worker assessment of queen fecundity. In support of this, Maisonnasse et al. (2010) found that queens whose mandibular glands had been removed (and thus produced minimal quantities of volatile pheromones) were still able to elicit a full response in workers. This suggests the involvement of other signals with a similar effect, and cuticular lipids are one possibility, though queens also have other sources of lipids such as the Dufour's gland (Richard et al., 2011a) and tergal glands (Wossler and Crewe, 1999). Cuticular hydrocarbons 
associated with fertility have also been experimentally demonstrated to affect worker behaviour and/or ovary development in at least five ant species, a wasp and a bumblebee (Holman et al., 2010; 2013; Smith et al., 2009; 2012; Van Oystaeyen et al., 2014), so it is entirely possible that cuticular lipids are similarly important in honeybees.

\section{ACKNOWLEDGEMENTS}

We were supported by the Australian Research Council (ARC) through a Queen Elizabeth II Fellowship and a Future Fellowship to BB, an ARC Linkage Project to BB and the ARC Centre of Excellence in Plant Energy Biology. We thank the honeybee keepers of Western Australia, especially Better Bees of Western Australia for providing the necessary honey bee material for this study. We also thank Tamara Hartke for statistical advice. 


\section{REFERENCES}

Akino T., Yamamura K., Wakamura S. and Yamaoka R. 2004. Direct behavioral evidence for hydrocarbons as nestmate recognition cues in Formica japonica (Hymenoptera : Formicidae). Appl. Entomol. Zool. 39: 381-387

Ayasse M., Marlovits T., Tengö J., Taghizadeh T. and Francke W. 1995. Are there pheromonal dominance signals in the bumblebee Bombus hypnorum L. (Hymenoptera, Apidae)? Apidologie 26: 163-180

Baer B., Heazlewood J.L., Taylor N.L., Eubel H., and Millar A.H. 2009. The seminal fluid proteome of the honeybee Apis mellifera. Proteomics 9: 2085-2097

Berger B., Camargo A.F. and da Cruz-Landim C. 2005. Effect of narcosis with $\mathrm{CO}_{2}$ on the ovarian development in queens of Apis mellifera (Hymenoptera, Apini). Sociobiology 48: 261-270

Blomquist G.J. and, Bagnères A.-G. (Eds) 2010. Insect Hydrocarbons: Biology, Biochemistry, and Chemical Ecology. Cambridge University Press, Cambridge

Blum M.S. (Ed) 1992. Honey Bee Pheromones. The Hive and the Honey Bee. Dadant \& Sons, Hamilton, Illinois

Brandstaetter A., Endler A. and Kleineidam C. 2008. Nestmate recognition in ants is possible without tactile interaction. Naturwissenschaften 95: 601-608

Breed M.D. 1998. Recognition pheromones of the honey bee. BioScience 48: 463-470

Bruschini C., Cervo R., Cini A., Pieraccini G., Pontieri L., Signorotti L. and Turillazzi S. 2011. Cuticular hydrocarbons rather than peptides are responsible for nestmate recognition in Polistes dominulus. Chem. Senses 36: 715-723

Copren K.A., Nelson L.J., Vargo E.L. and Haverty M.I. 2005. Phylogenetic analyses of mtDNA sequences corroborate taxonomic designations based on cuticular hydrocarbons in subterranean termites. Mol. Phylogenet. Evol. 35: 689-700

Cronin A.L. and Monnin T. 2010. Self-sacrifice in 'desperado' contests between relatives. Front. Zool. 7: 27

Crozier R.H. and Dix M.W. 1979. Analysis of two genetic models for the innate components of colony odor in social Hymenoptera. Behav. Ecol. Sociobiol. 4: 217-224

Cuvillier-Hot V., Cobb M., Malosse C. and Peeters C. 2001. Sex, age and ovarian activity affect cuticular hydrocarbons in Diacamma ceylonense, a queenless ant. J. Ins. Physiol. 47: 485-493

d'Ettorre P. and Heinze J. 2005.Individual recognition in ant queens. Curr. Biol. 15:2170-2174

da Cruz-Landim C., Patricio K. and Antonialli W.F. . 2006. Cell death and ovarian development in highly eusocial bees (Hymenoptera, Apidae): Caste differentiation and worker egg laying. Braz. J. Morphol. Sci. 23: 27-42.

Dani F.R. 2009. Cuticular lipids as semiochemicals in paper wasps and other social insects. Ann. Zool. Fennici 43: 500-514

Dani F.R., Jones G.R., Corsi S., Beard R., Pradella D. and Turillazzi S. 2005. Nestmate recognition cues in the honey bee: Differential importance of cuticular alkanes and alkenes. Chem. Senses 30: 477-489

Dapporto L., Fondelli L. and, Turillazzi S. 2006. Nestmate recognition and identification of cuticular hydrocarbons composition in the swarm founding paper wasp Ropalidia opifex. Biochem. Syst. Ecol. 34: 617-625 
de Biseau J.C., Passera L., Daloze D. and Aron S. 2004. Ovarian activity correlates with extreme changes in cuticular hydrocarbon profile in the highly polygynous ant, Linepithema humile. J. Ins. Physiol. 50: 585-593

Dietemann V., Peeters C., Liebig J., Thivet V. and Hölldober B. 2003. Cuticular hydrocarbons mediate discrimination of reproductives and nonreproductives in the ant Myrmecia gulosa. Proc. Natl. Acad. Sci. USA 100: 10341-10346

Gibbs A.G. 2002. Lipid melting and cuticular permeability: new insights into an old problem. J. Ins. Physiol. 48: 391-400

Grozinger C.M., Sharabash N.M., Whitfield C.W. and Robinson G.E. 2003. Pheromone-mediated gene expression in the honey bee brain. Proc. Natl. Acad. Sci. USA 100: 14519-14525

Holman L., Jørgensen C.G., Nielsen J. and d'Ettorre P. 2010. Identification of an ant queen pheromone regulating worker sterility. Proc. $R$. Soc. B. 277: 3793-3800.

Holman L., Lanfear R. and d'Ettorre P. 2013. The evolution of queen pheromones in the ant genus Lasius. J. Evol. Biol. 26: 1549-1558

Hoover S.R., Keeling C., Winston M. and Slessor K. 2003. The effect of queen pheromones on worker honey bee ovary development. Naturwissenschaften 90: $477-480$

Howard R.W. and Blomquist G.J. 2005. Ecological, behavioral and biochemical aspects of insect hydrocarbons. Annu. Rev. Entomol. 50: 371-393

Kather R., Drijfhout F. and, Martin S. 2011. Task group differences in cuticular lipids in the honey bee Apis mellifera. J. Chem. Ecol. 37: 205-212

Keeling C.I., Slessor K.N., Higo H.A. and Winston M.L. 2003. New components of the honey bee (Apis mellifera L.) queen retinue pheromone. Proc. Natl. Acad. Sci. USA 100: 4486-4491

Keller L. and Nonacs P.1993. The role of queen pheromones in social insects: queen control or queen signal? Anim. Behav. 45: 787-794

Kocher S.D., Richard F.-J., Tarpy D.R. and Grozinger C.M. 2009. Queen reproductive state modulates pheromone production and queen-worker interactions in honeybees. Behav. Ecol. 20: 1007-1014

Kocher S.D., Richard F.J., Tarpy D.R. and Grozinger C.M. 2008. Genomic analysis of post-mating changes in the honey bee queen (Apis mellifera). BMC Genomics 9: 232

Kocher S.D., Tarpy D.R. and Grozinger C.M. 2010. The effects of mating and instrumental insemination on queen honey bee flight behaviour and gene expression. Ins. Mol. Biol. 19: 153-162

Laidlaw H.H. and Page R.E. 1997. Queen Rearing and Bee Breeding. Wicwas Press, Cheshire, Connecticut

Le Conte Y. and, Hefetz A. 2008. Primer pheromones in social hymenoptera. Annu. Rev. Entomol. 53: 523-542

Liebig J., Peeters C., Oldham N.J., Markstädter C. and, Hölldober B. 2000. Are variations in cuticular hydrocarbons of queens and workers a reliable signal of fertility in the ant Harpegnathos saltator? Proc. Natl. Acad. Sci. USA 97: 41244131

Lockey K.H. 1988. Lipids of the insect cuticle: origin, composition and function. Comp. Biochem. Phys. B 89: 595-645

Lorenzi M.C., Bagneres A.G. and, Clement J.L. 1996. The Role of Cuticular Hydrocarbons in Social Insects: Is It the Same in Paper Wasps? In: Turillazzi S. and, West-Eberhard M.J. (Eds) Natural History and Evolution of Paper Wasps. Oxford University Press, Oxford, pp 178-189 
Mackenson O. 1964. Relation of semen volume to success in artificial inseminated of queen honey bees. J. Econ. Entomol. 57: 581-583

Maisonnasse A., Alaux C., Beslay D., Crauser D., Gines C., Plettner E. and, Le Conte Y. 2010. New insights into honey bee (Apis mellifera) pheromone communication. Is the queen mandibular pheromone alone in colony regulation? Front. Zool. 7:18

Mattila H.R., Reeve H.K. and Smith M.L. 2012. Promiscuous honey bee queens increase colony productivity by suppressing worker selfishness. Curr. Biol. 22: 2027-2031

Monnin T. 2006. Chemical recognition of reproductive status in social insects. Finn. Zool. Bot. Publ. Board 43: 515-530

Mueller J.K., Eggert A.-K. and Elsner T. 2003. Nestmate recognition in burying beetles: The "breeder's badge" as a cue used by females to distinguish their mates from male intruders. Behav. Ecol. 14: 212-220

Niño E.L., Malka O., Hefetz A., Tarpy D.R. and Grozinger C.M. 2013. Chemical profiles of two pheromone glands are differentially regulated by distinct mating factors in honey bee queens (Apis mellifera.). PLoS ONE 8: e78637

Nino E.L., Malka O., Hefetz A., Teal P., Hayes J. and Grozinger C.M. 2012. Effects of honey bee (Apis mellifera L.) queen insemination volume on worker behavior and physiology. J. Ins. Physiol. 58: 1082-1089

Nunes T.M., Nascimento F.S., Turatti I.C., Lopes N.P. and Zucchi R. 2008. Nestmate recognition in a stingless bee: Does the similarity of chemical cues determine guard acceptance? Anim. Behav. 75: 1165-1171

Peeters C. and Liebig J. 2009. Fertility signaling as a general mechanism of regulating reproductive division of labor in ants. In: Gadau J, Fewell J (Eds) Organization of Insect Societies: From Genome to Sociocomplexity. Harvard University Press, Cambridge, pp 220-242

Peeters C., Monnin T. and Malosse C. 1999. Cuticular hydrocarbons correlated with reproductive status in a queenless ant. Proc. $R$. Soc. B. 266: 1323-1327

Rangel J. and Seeley T.D. 2008. The signals initiating the mass exodus of a honeybee swarm from its nest. Anim. Behav. 76: 1943-1952

Richard F.-J., Schal C., Tarpy D.R. and Grozinger C.M. 2011a. Effects of instrumental insemination and insemination quantity on dufour's gland chemical profiles and vitellogenin expression in honey bee ueens (Apis mellifera). J. Chem. Ecol. 37: 1027-1036

Richard F.-J., Tarpy D.R. and, Grozinger C.M. 2007. Effects of insemination quantity on honey bee queen physiology. PLoS ONE 2: e980

Richard F.-J., Schal C., Tarpy D.R. and, Grozinger C.M. 2011b. Effects of instrumental insemination and insemination quantity on dufour's gland chemical profiles and vitellogenin expression in honey bee queens (Apis mellifera). J. Chem. Ecol. 37: 1027-1036

Ruttner F. 1976. The Instrumental Insemination of the Queen Bee. International Beekeeping Technology and Economy. Institute, 2 Edn. Apimondia, Bucharest.

Seeley T.D. 1995. The Wisdom of the Hive: The Social Physiology of Honey Bee Colonies. Harvard University Press, Cambrige, MA

Seeley T.D., Visscher P.K. and Passino K.M. 2006. Group decision making in honey bee swarms. Am. Sci. 94: 220-229

Singer T.L. 1998. Roles of hydrocarbons in the recognition systems of insects. Am. Zool. 38: 394-405 
Sledge M.F., Boscaro F. and Turillazzi S. 2001. Cuticular hydrocarbons and reproductive status in the social wasp Polistes dominulus. Behav. Ecol. Sociobiol. 49: 401-409

Slessor K.N., Kaminski L.-A., King G.G.S., Borden J.H. and Winston M.L. 1988. Semiochemical basis of the retinue response to queen honey bees. Nature 332: 354-356

Smith A.A., Hölldober B. and Liebig J. 2009. Cuticular hydrocarbons reliably identify cheaters and allow enforcement of altruism in a social insect. Curr. Biol. 19: 78-81

Smith A.A., Millar J.G., Hanks L.M. and Suarez A.V. 2012. Experimental evidence that workers recognize reproductives through cuticular hydrocarbons in the ant Odontomachus brunneus. Behav. Ecol. Sociobiol. 66: 1267-1276

Strauss K., Scharpenberg H., Crewe R., Glahn F., Foth H. and Moritz R. 2008. The role of the queen mandibular gland pheromone in honeybees (Apis mellifera): Honest signal or suppressive agent? Behav. Ecol. Sociobiol. 62: 1523-1531

Tarpy D.R. and Mayer M.K. 2009. The effects of size and reproductive quality on the outcomes of duels between honey bee queens (Apis mellifera L.). Ethol. Ecol. Evol. 21: 147-153

Thomas M.L. and Simmons L.W. 2009. Male-derived cuticular hydrocarbons signal sperm competition intensity and affect ejaculate expenditure in crickets. Proc. R. Soc. B 276: 383-388

Thomas M.L. and Simmons L.W. 2011. Crickets detect the genetic similarity of mating partners via cuticular hydrocarbons. J. Evol. Biol. 24: 1793-1800

Van Oystaeyen, A., Oliveira, R. C., Holman, L., van Zweden, J. S., Romero, C., Oi, C. A, d'Ettorre, P., Khalesi, M., Billen, J., Wäckers, F., Millar, J.G., and Wenseleers, T. 2014. Conserved class of queen pheromones stops social insect workers from reproducing. Science 343: 287-290.

van Wilgenburg E., Symonds M.R.E. and, Elgar M.A. 2011. Evolution of cuticular hydrocarbon diversity in ants. J. Evol. Biol. 24: 1188-1198

van Zweden J. and d'Ettore P. 2010. Nestmate Recognition in Social Insects and the Role of Hydrocarbons. In: Blomquist G.J. and, Bagneres A.G. (Eds.) Insect Hydrocarbons: Biology, Biochemistry, and Chemical Ecology. Cambridge University Press, Cambridge

Vergoz V., Schreurs H.A. and Mercer A.R. 2007. Queen pheromone blocks aversive learning in young worker bees. Science 317: 384-386

Wanner K.W., Nichols A.S., Walden K.K.O., Brockmann A., Luetje C.W. and Robertson H.M. 2007. A honey bee odorant receptor for the queen substance 9-oxo-2-decenoic acid. Proc. Natl. Acad. Sci. USA 104: 14383-14388

Welch M.D., and Lister R. (2014) Epigenomics and the control of fate, form and function in social insects. Curr. Opin. Insect Sci. 1: 31-38

Winston M.L. 1987. The Biology of the Honey Bee. Harvard University Press, Cambridge, Massachusettes

Wossler T.C. and Crewe R.M. 1999. Honeybee queen tergal gland secretion affects ovarian development in caged workers. Apidologie 30: 311-320 


\section{FIGURE LEGENDS}

Figure 1: Representative gas chromatogram from a 10-day-old, semeninseminated queen. Peaks used in the study are numbered as in Table S1. The asterisk marks the internal standard, $n$-docosane.

Figure 2: The effect of age and insemination treatment on the abundance of individual saturated hydrocarbons, unsaturated hydrocarbons, and wax esters on queen cuticle. Bars indicate means $\pm 1 \mathrm{SE}$, and the $\mathrm{y}$-axis shows an approximation of the total mass of the chemical on the cuticle in micrograms.

Figure 3: The proportion of the lipid profile composed of saturated hydrocarbons, unsaturated hydrocarbons and wax esters is affected by queen age, and to a lesser extent by insemination treatment. The bars show means \pm 1 SE, and the y-axis shows the relative amount of each chemical family in the total profile as a percentage.

Figure 4: Multivariate analysis of lipid profiles revealed strong effects of queen age in virgin queens (panel A), but no effect of insemination treatment (panel B). The axes show the first two non-metric multidimensional scaling (NMDS) scores. 
Figure 1

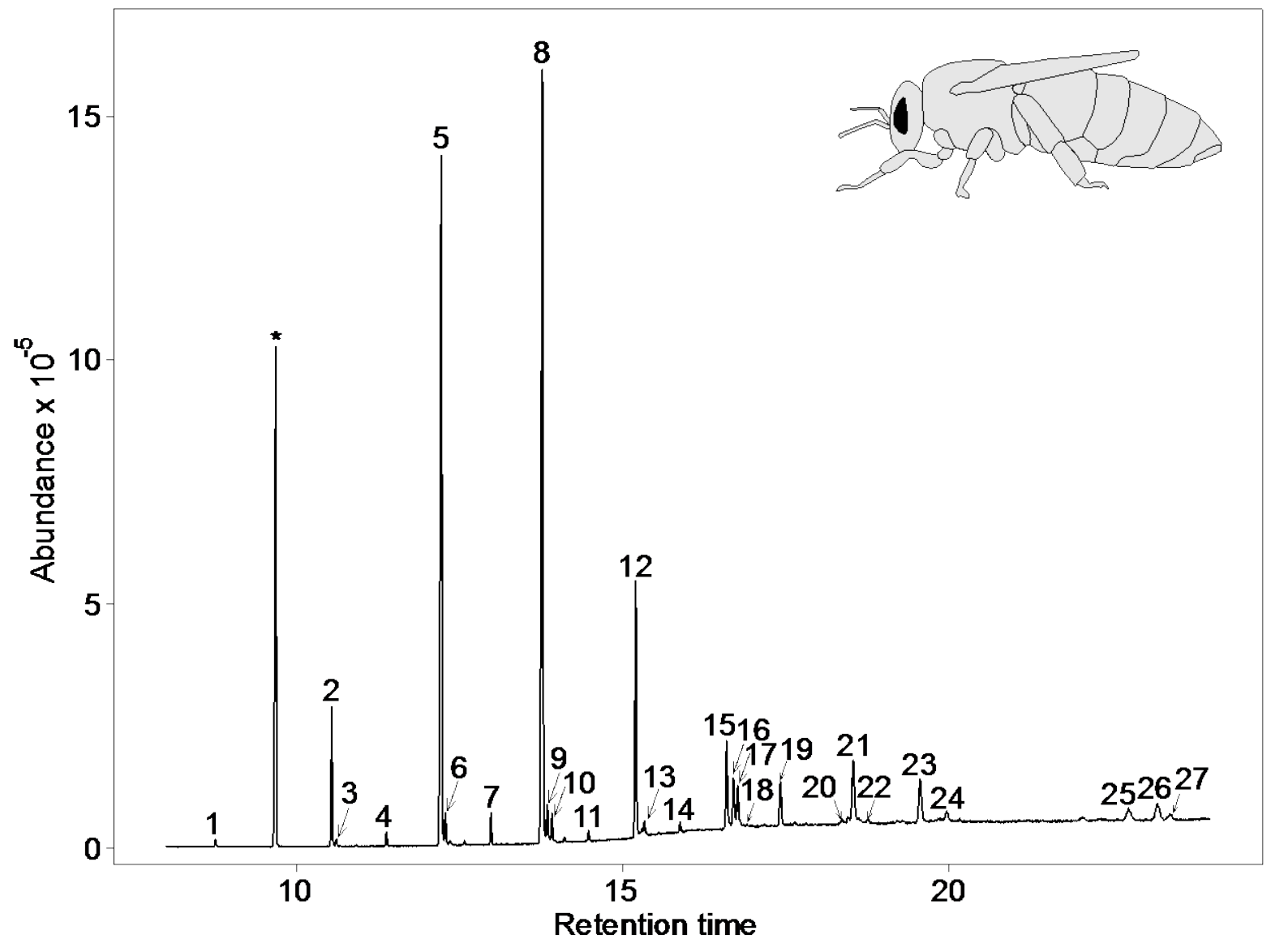


Figure 2
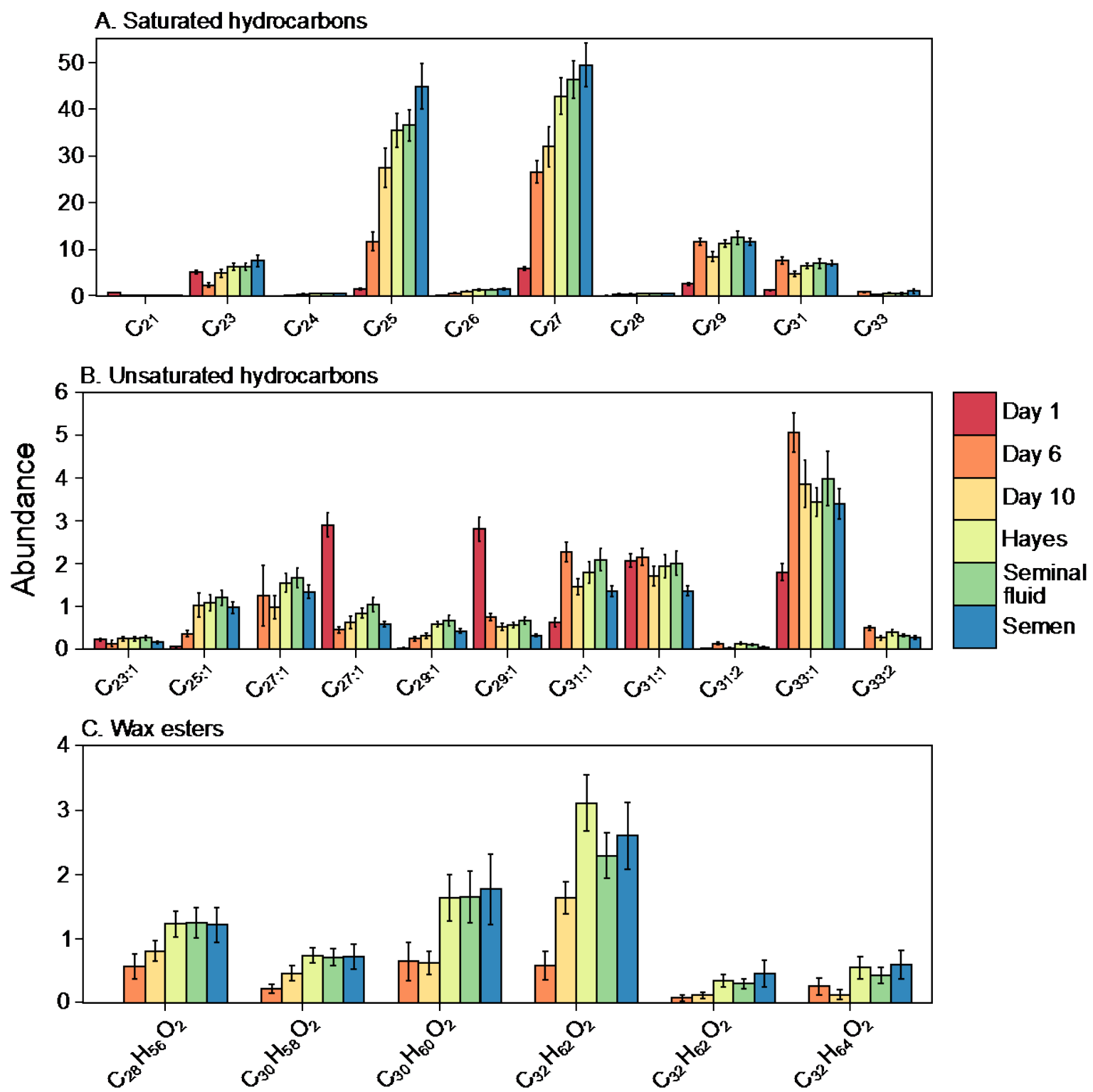
Figure 3

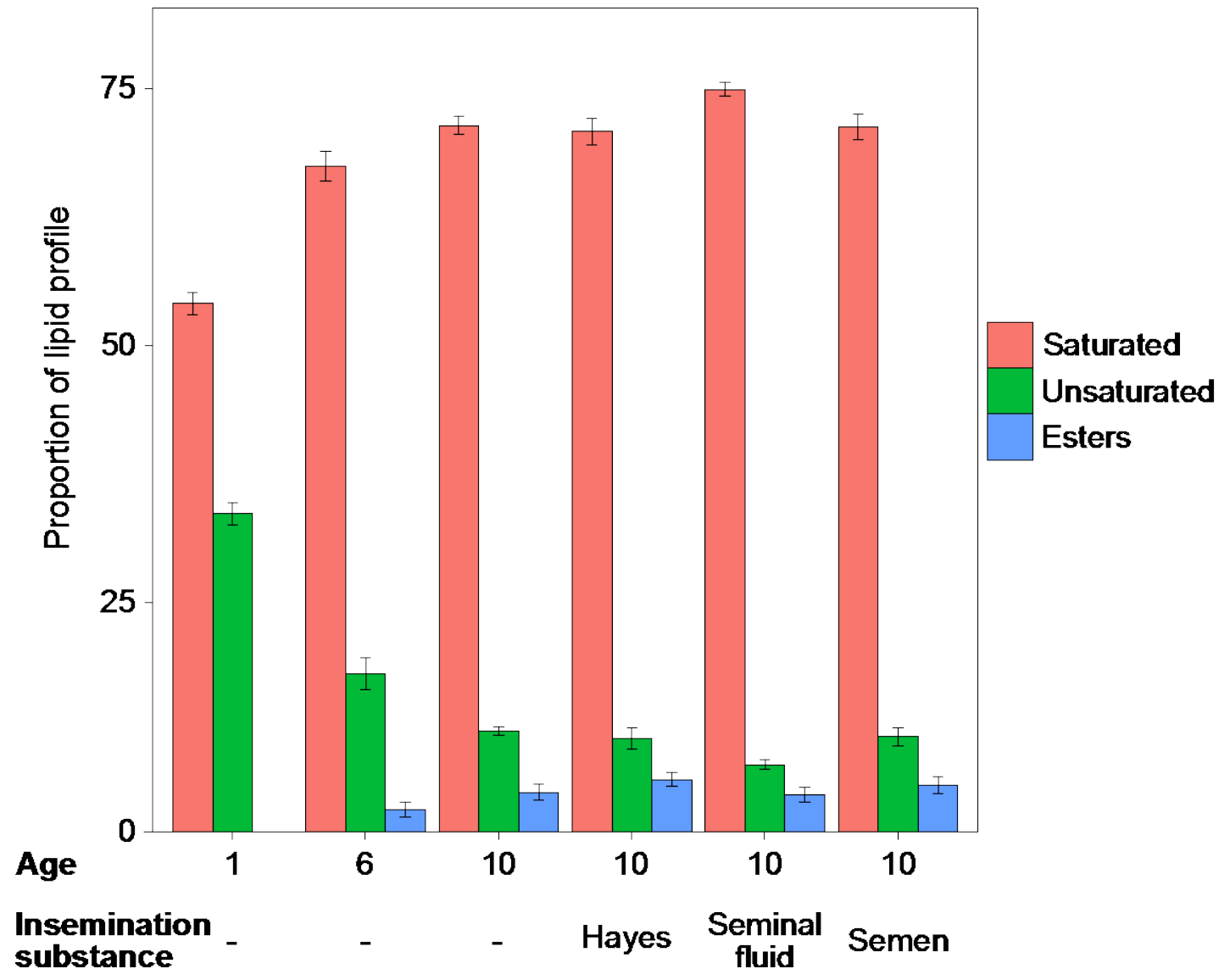


Figure 4

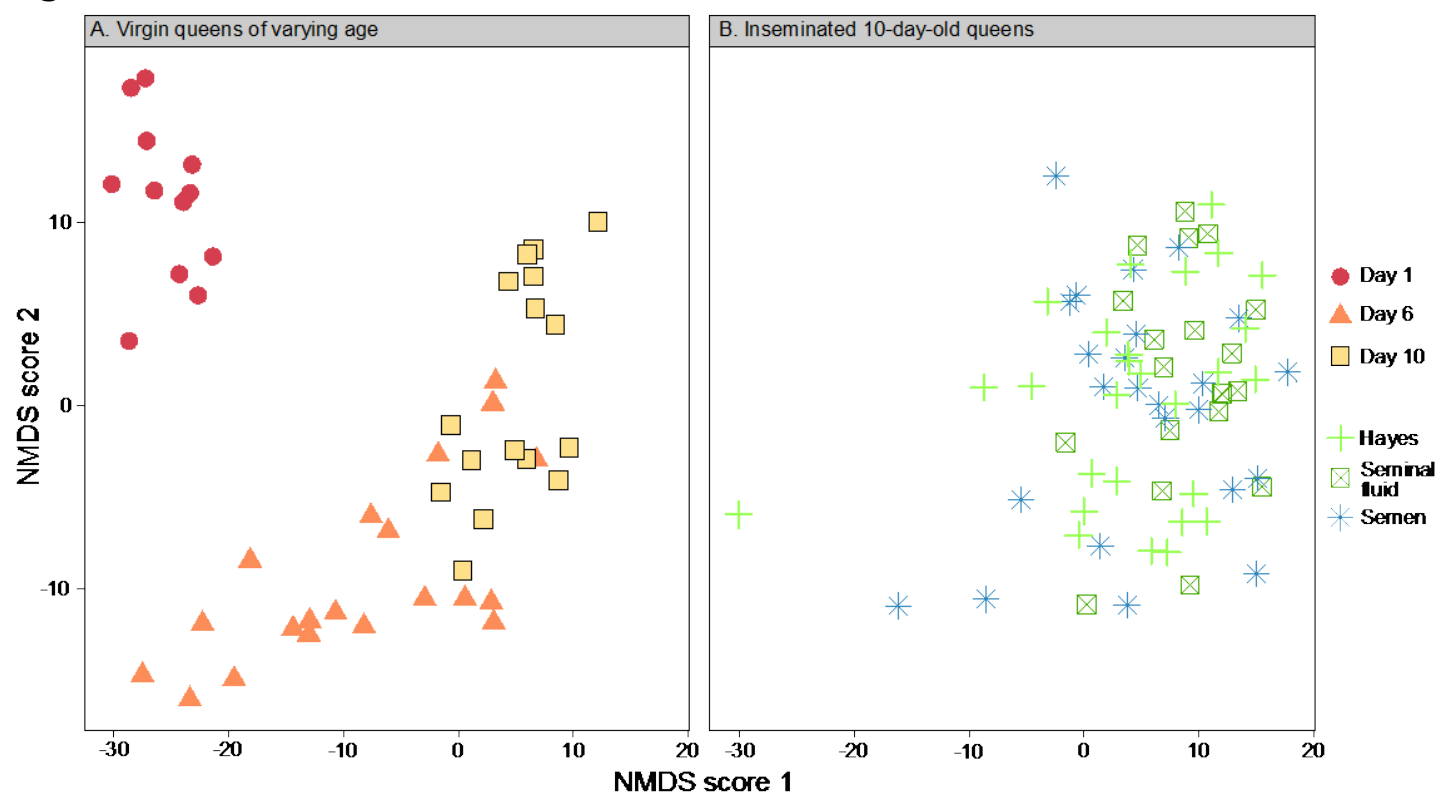




\section{SUPPLEMENTARY DATA}

Table S1: Abundance (relative to internal standard) of the 27 compounds identified from the cuticle of one-, six- and ten-day-old virgin honeybee queens (Apis mellifera), and ten-day-old queens inseminated with Hayes, seminal fluid or semen. Compounds whose abundance is shown in bold in the third column changed significantly with age at $\mathrm{p}<0.001$. The compound whose abundance is shown in bold in the sixth column was significantly affected by insemination treatment with $\mathrm{p}<0.001$. 


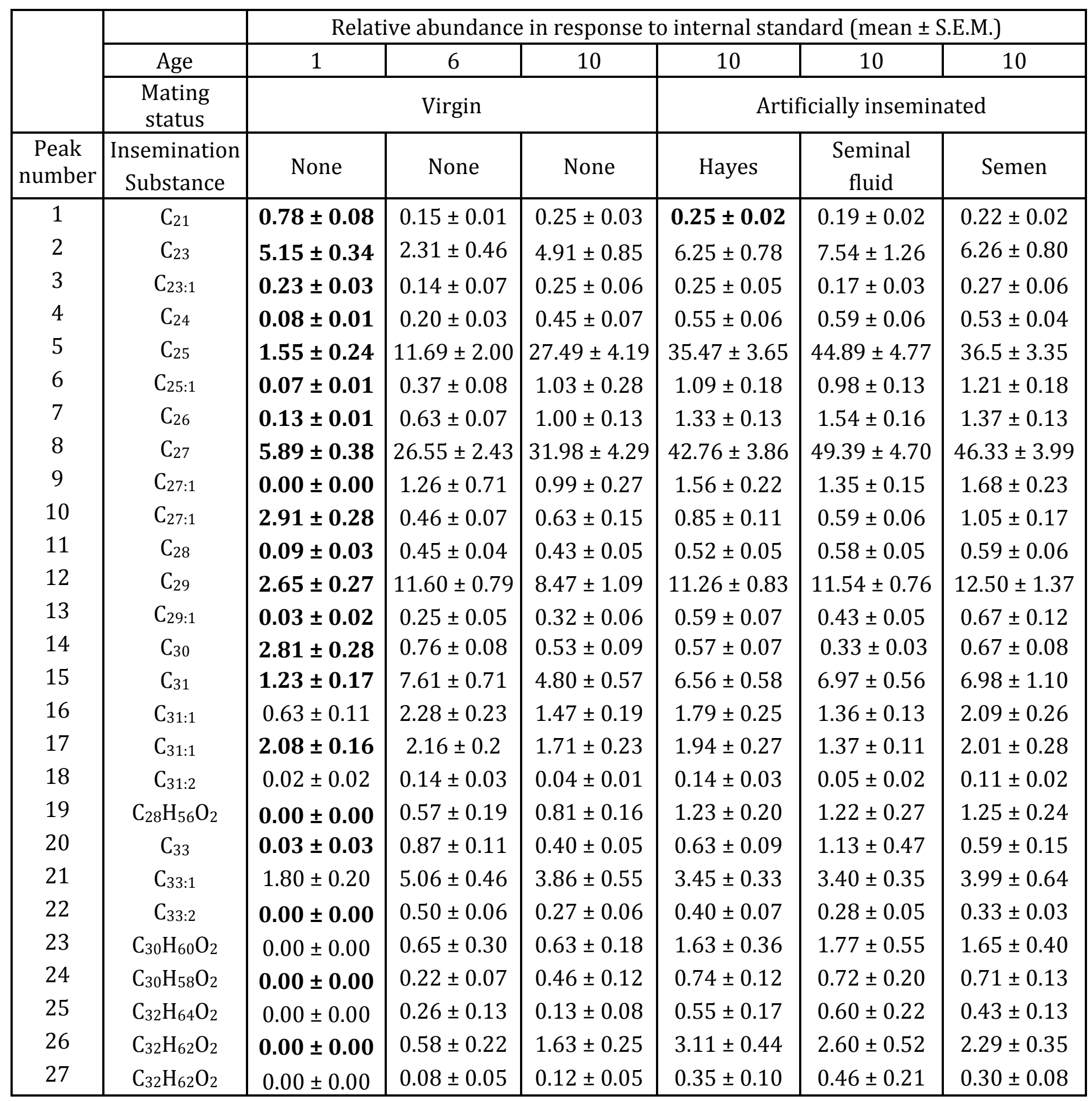

